\title{
NORMATIVIDADE, DESCONSTRUÇÃO E JUSTIÇA: para além do dever ser na Base Nacional Comum da Formação de Professores
}

\author{
Hugo Heleno Camilo Costa \\ Universidade Federal de Mato Grosso- UFMT, Brasil \\ Érika Virgílio Rodrigues da Cunha \\ Universidade Federal de Rondonópolis- UFR, Brasil
}

\begin{abstract}
Resumo
O artigo foca a relação entre a Resolução CNE/CP N. ${ }^{\circ} 02$ de 20 de dezembro de 2019 e a Base Nacional Comum Curricular para a educação básica para problematizar a busca por fundamentação curricular através da decisão pela normatividade como justificativa para a garantia de acesso ao direito à educação para determinado sujeito. Na primeira seção, desenvolvemos um diálogo no campo dos estudos curriculares recentes pondo-o em tensão com a proposta restritiva de currículo comum. Focalizamos, especificamente, a relação entre a afirmação do direito com a perspectiva de um sujeito a recebê-lo, para questionar a defesa normativa do acesso a determinado conhecimento como condição para ser sujeito, educado, cidadão. Duas seções são apresentadas, na sequência, mobilizando, respectivamente, contribuições pós-estruturais de Laclau e Derrida, atentando para a potência interpretativa de noções como democracia e normatividade, desconstrução e justiça. Nas conclusões, a perspectiva de base comum é afirmada como antidemocrática e apartada da justiça, por pautar a subjetividade ao dever ser, por visar restringir a diferença ao comum e transparente.
\end{abstract}

Palavras-chave: Base comum; Políticas de currículo; Formação de professores.; Normatividade.

\begin{abstract}
The article focuses on the relationship between CNE / CP Resolution No. 02 of December 20, 2019 and the Common Curriculum Base of Elementary School to problematize the search for curricular foundation through the decision without normativity as a justification for guaranteeing access to the right year of education for a given discipline. In the first section, we develop a dialogue in the field of two recent curricular studies that I have placed in tension as a restrictive proposition of the common curriculum. We specifically focus on the relationship between a direct statement with the perspective of a subject to receive it, to question the defense of the norms of access to certain knowledge as a condition for being a subject, educated, citizen. Two sections are presented, in sequence, mobilizing, respectively, post-structural contributions by Laclau and Derrida, paying attention to the interpretative power of notions such as democracy and normativity, deconstruction and justice. In the conclusions, the common base perspective is affirmed as undemocratic and separated from justice, as it guides subjectivity to what it should be, as it seeks to restrict difference to the common and transparent.
\end{abstract}

Keywords: Common base; Curriculum Policies; Teacher training; Normativity.

ISSN 1645-1384 (online) www.curriculosemfronteiras.org 


\section{Introdução}

Esta discussão, que está envolvida no amplo movimento de oposição a bases ou currículos nacionais, tem seu foco principal na relação entre a Base Nacional Comum para a Formação Inicial de Professores da Educação Básica (BNC-Formação) e a Base Nacional Comum Curricular da Educação Básica. Afastado de uma busca pela correção do texto da BNC-Formação - de apontamentos de elementos faltosos ou irregulares a serem corrigidos na política -, o artigo se constitui no questionamento à busca por fundamentação curricular que marca a atual política de formação de professores no Brasil em sua decisão pelo aumento da normatividade.

Desde a produção e aprovação, em 2017, de uma Base Nacional Comum Curricular (BRASIL, 2017), lidamos com uma acentuação da prescrição nas políticas para a Educação Básica sob a justificativa da garantia de acesso ao direito à educação, para determinado sujeito. Já na apresentação da BNCC da Educação Básica, os elaboradores julgam oferecer ao país uma "[...] proposta de direitos e objetivos de aprendizagem e desenvolvimento para os alunos da Educação Básica, pactuada com os Estados, o Distrito Federal e os Municípios." (BRASIL, 2017, p.4). É mobilizada uma ampla expectativa acerca dos direitos das crianças e jovens em idade escolar, também por meio da evocação do Artigo 205 da Constituição Federal de 1988, que define a educação como direito de todos e dever do Estado e da família, a ser "[...] promovida e incentivada com a colaboração da sociedade, visando ao pleno desenvolvimento da pessoa, seu preparo para o exercício da cidadania e sua qualificação para o trabalho." (BRASIL, 1988). Além da prerrogativa do direito substantivo constitucional, tenta-se respaldar a política curricular, ainda, por referência aos direitos das crianças e adolescentes, dispostos na Lei $\mathrm{n}^{\circ}$ 8.069/1990 (Estatuto da Criança e do Adolescente), bem como ao se anunciar a educação em direitos humanos prevista no Decreto $\mathrm{n}^{\circ} 7.037$, de 21 de dezembro de 2009, que instituiu o Programa Nacional de Direitos Humanos.

A adoção de uma noção instrumental de competência é justificada "[...] no sentido da mobilização e aplicação dos conhecimentos escolares" (BRASIL, 2017, p. 16), com o apelo de que tais conhecimentos sejam "[...] entendidos de forma ampla (conceitos, procedimentos, valores e atitudes), [pois] ser competente significa ser capaz de, ao se defrontar com um problema, ativar e utilizar o conhecimento construído" (Idem). A competência, como instância de simplificação do que seja direito, é citada repetidamente para "[...] reafirmar o compromisso da BNCC com a garantia de que os direitos de aprendizagem sejam assegurados a todos os alunos", por meio "[...] (d)a indicação clara do que os alunos devem saber, e, sobretudo, do que devem saber fazer como resultado de sua aprendizagem oferece(ndo) referências para o fortalecimento de ações que assegurem esses direitos" (BRASIL, 2017, p. 15). Assim, a simplificação da noção de direito substantivo fundamental, de direito humano, a direito de aprender conhecimentos considerados essenciais, ensaia a dispensa de "[...] um modelo obrigatório para o desenho dos currículos." (p. 29), reiterando as competências como a promessa de acesso a uma transparência primeira do que seria ensinar e aprender, afiançando-se que 
A forma de apresentação adotada na BNCC tem por objetivo assegurar a clareza, a precisão e a explicitação do que se espera que todos os alunos aprendam na Educação Básica, fornecendo orientações para a elaboração de currículos em todo o País, adequados aos diferentes contextos. (BRASIL, 2017, p. 29).

A homologação da Resolução CNE/CP N. 02 de 20 de dezembro de 2019, que revoga a Resolução CNE/CP N. 02 de 01 de julho de 2015 (BRASIL, 2015) e define as Diretrizes Curriculares Nacionais para a Formação Inicial de Professores para a Educação Básica e institui a Base Nacional Comum para a Formação Inicial de Professores da Educação Básica (BNC-Formação) coroa este cenário de estreitamento curricular ao alinhar a formação de professores ao currículo comum da escolarização básica. O Art. $6^{\circ}$ da Resolução CNE/CP N. ${ }^{\circ}$ 02/2019 busca dar vulto à ideia de garantia de direito fundamental, afirmando que

A política de formação de professores para a Educação Básica, em consonância com os marcos regulatórios, em especial com a BNCC, tem como princípios relevantes: I - a formação docente para todas as etapas e modalidades da Educação Básica como compromisso de Estado, que assegure o direito das crianças, jovens e adultos a uma educação de qualidade, mediante a equiparação de oportunidades que considere a necessidade de todos e de cada um dos estudantes. (BRASIL, 2019a).

A enunciação do direito à educação de qualidade na Resolução CNE/CP N. ${ }^{\circ}$ 02/2019 se espraia pelas ideias de respeito ao direito de aprender dos licenciandos e de seus futuros alunos, de reconhecimento do direito de aprender dos ingressantes, de direitos humanos, de direitos de aprendizagem e desenvolvimento da BNCC e, por fim, do direito assegurado de concluir a formação sob uma mesma orientação curricular. Tais inscrições são justificadas pela crença de que uma política de formação deve garantir "Art. $7^{\circ}$ - A organização curricular dos cursos destinados à Formação Inicial de Professores para a Educação Básica, em consonância com as aprendizagens prescritas na BNCC da Educação Básica [...]” (BRASIL, 2019a). Essa interpretação contingente - e não inexorável - da política, que apaga as implicações de uma discussão sobre formação de professores e sobre o direito à educação em seu caráter amplo ou para além de uma redução do direito a conhecimentos, autoriza a perspectiva de que "[...] a BNCC-Educação Básica deve contribuir para a articulação e a coordenação das políticas e ações educacionais em relação à formação de professores" (Idem).

Ao destacarmos este cenário em atenção à chamada para publicação na Seção Temática Dispositivos de Regulação da Docência nas Políticas de Currículo, reafirmamos os inúmeros movimentos críticos a tais políticas no país. Em agosto de 2021 foi aprovada, pelo Pleno do Conselho Nacional de Educação, a dilatação do prazo, até dezembro de 2022, para a adequação dos cursos de licenciatura à Resolução CNE/CP N. ${ }^{\circ}$ 02/2019. A agenda contra a prescrição curricular vem sendo duramente problematizada e combatida nos últimos tempos por entidades da área da educação ${ }^{1}$. Não é demais lembrar como a aprovação das políticas em tela, pelo Conselho Nacional de Educação, se fez indiferente a atuação incisiva de 
associações científicas e de classe na reivindicação de atenção à vasta produção acadêmica da área e de ampliação do debate público, como salientam Costa, Rodrigues e Stribel (2019), Macedo (2015) e Valle (2020), uma vez que as regulamentações passaram a ser definidas $a$ portas fechadas para as lutas históricas na área. O questionamento do caráter neoliberal dessas investidas na ampliação para a atuação do setor privado no âmbito público, bem como da lógica economicista que reveste o projeto educativo das bases comuns tem sido objeto de atenção crescente entre os pesquisadores (GREGOL; LOPES, 2021; MACEDO, 2014; TARLAU; MOELLER, 2020). A Associação Nacional pela Formação dos Profissionais da Educação (ANFOPE), a Associação Nacional de Pós-graduação e Pesquisa em Educação (ANPEd) e a Associação Brasileira de Currículo (ABdC) são algumas dessas entidades que, mais recentemente, se articulam no enfrentamento a essas políticas juntamente com a Associação Nacional dos Dirigentes das Instituições Federais de Ensino Superior (ANDIFES) e o Grupo de Trabalho da Sociedade Brasileira para o Progresso da Ciência (SBPC), dentre outras.

No escopo deste movimento crítico, não postulamos a inexistência do normativo tampouco da ideia de direito à educação. Pensamos a educação como um campo de disposições construídas, por entendermos que "Nós sempre estamos já [sob/] dentro de uma certa ordem normativa [...]. Vivemos em meio a práticas sociais sedimentadas que limitam o campo do que é pensável e decidível" (LACLAU, 2004, p. 162). Assim, pretendemos questionar a normatividade exacerbada nas políticas - em articulação com uma discussão do campo (LOPES, 2015a; 2017; CUNHA; COSTA; BORGES, 2018; PEREIRA, 2019; LOPES; MACEDO, 2021) -, por compreendermos que o sujeito da educação (estudantes, professores) emerge em contextos interpretativos e, portanto, relacionais, jamais contornáveis em definitivo pela norma como excessiva presunção de dever ser à educação, ao ensino, ao conhecimento, à identidade. Assim, não nos situamos fora do normativo e, igualmente, nos sabemos imersos na busca pela construção de vias de comunicação com o outro, reconhecendo, pois, que estamos todos (sempre) implicados na tentativa de produção de léxicos, de proposição de códigos, de defesa de segurança para, de algum modo, conjecturarmos caminhos. Pensamos, então, que a busca por uma qualquer perspectiva (e da educação relacionada ao direito) só se faz pela sensação de que a alteridade não é apreensível pela normatividade que apregoamos e, ao mesmo tempo, defendemos que nossas militâncias não podem se constituir na aspiração ao fechamento de significados, de fixação do outro, de impedimento às rasuras, de controle sobre a diferença que não se permite controlar.

A mobilização desses argumentos enseja, portanto, uma complicação à ideia de normatividade curricular que buscamos enfrentar neste texto. Nossa leitura é de que a normatividade curricular na política de formação de professores (BNC-Formação), alinhada à BNCC da educação básica, constitui dispositivos de regulação da docência que limitam o entendimento do que seja educar, destituindo a autonomia de professores, escolas e cursos universitários de formação de professores. Tais dispositivos são instados, principalmente, pela perspectiva de que professores de todas as escolas brasileiras devem dominar a linguagem instrumental (e, por vezes, crítica) defendida pelos elaboradores de políticas, por aderência a um código de eficiência que faz transitar a ideia de direito a aprender. Tal 
linguagem é suscitada como inovadora por fazer referência a proposta de direitos e objetivos de aprendizagem e desenvolvimento para os alunos da Educação Básica, num desdobramento curricular mecanicista, no qual objetivos de aprendizagem estão conectados a objetos de conhecimento, a competências e a habilidades pra serem verificados, no futuro, por meio de códigos alfanuméricos nas avaliações do desempenho dos estudantes. A discussão é mobilizada por uma inspiração desconstrucionista, para pôr em questão o terreno em que operam as tentativas de aumento da regulação em nome do direito $a$.

Assim sendo, na primeira seção deste artigo, para dar curso a essa problematização, desenvolvemos um diálogo no campo dos estudos curriculares pondo-o em tensão com a proposta restritiva de currículo comum, que alinha a formação inicial e continuada de professores à Educação Básica. Focalizamos, especificamente, a relação entre a afirmação do direito com a perspectiva de um sujeito a recebê-lo, interpelando a defesa normativa do acesso a determinado conhecimento como condição para ser sujeito, educado, cidadão. Tomamos as ideias de sujeito, currículo, conhecimento, educação e democracia (termos caros à política curricular em questão), como nomes de sentidos fugidios às certezas de uma razão normativa, por considerarmos potente a reflexão sobre movimentos pretendidos à significação última destes termos e, particularmente, a sua relação com democracia e justiça na reiteração do direito $a$.

A potência referida acima nos leva à segunda seção, na qual defendemos uma interpretação pós-estrutural da normatividade na luta política, marcada pela relação com a alteridade. Para isto, a partir de Laclau e Derrida, é desenvolvida uma reflexão sobre o normativo, em sua busca pela constituição de uma plenitude funcional e/ou corretiva para o outro, em relação à contemporaneidade deste pensamento de fundo (e de finalidade) nas políticas em questão, com foco na problematização do dever ser endereçado ao outro que escapa. Assim, ao ponderarmos a questão da democracia e da plenitude ausente no discurso normativo na defesa do que ( $m e$ ) falta como norma para o outro, Laclau (2004) nos possibilita discutir como, na relação entre normatividade e direito, estão em foco o dever ser, como afirmação cara à expectativa do normativo, e o sendo/ser, como de uma ordem descritiva, não apreensível pela normatividade.

Em uma última seção, realçamos as ideias de justiça (como nome dinâmico na defesa ao direito ao/do sujeito), violência, différance e decisão, entendo-as como meios pelos quais se torna viável a reedição dos termos do debate sobre os direitos à educação, de ser (no) currículo. A justiça é sinalizada, com Derrida, como violência traduzida à normatividade e à desconstrução, num movimento caro à opacidade da linguagem. Desta forma, esse movimento sob o qual só se pode investir é pensado pelo autor como tradução: dinâmica traidora daquilo mesmo que se julga proteger, do sentido que se quer assegurar ou precisar na relação com o outro (DERRIDA, 2010). Nas conclusões, a perspectiva de base comum é afirmada como marcada por sentidos antidemocráticos e apartada da justiça, por pautar a subjetividade ao dever ser. 


\section{O direito como dever ser e o sujeito a recebê-lo na pretensão de um currículo comum}

Nosso envolvimento interpretativo à BNCC-Formação é iniciado por sua problematização como pretensão de normatividade instauradora de um dever ser que confere aos cursos de licenciatura a responsabilidade de garantir o princípio da "I - a formação docente para todas as etapas e modalidades da Educação Básica como compromisso de Estado, que assegure," conforme o Art. $6^{\circ}$, "o direito das crianças, jovens e adultos a uma educação de qualidade, mediante a equiparação de oportunidades que considere a necessidade de todos e de cada um dos estudantes". Atentamos para as discussões de Lopes (2015a; 2015b) e Macedo (2016; 2017), para as quais, desde uma orientação pós-fundacional laclauniana e pós-estrutural derridiana, há uma exacerbação normativa nas políticas atuais. Como explica Lopes, uma pretensão universalizante para a educação, coordenada por enfoques racionalistas (2015a), opera "a redução da política curricular à política de conhecimento a ser ensinado/aprendido nas escolas" (2015b, p. 118). Trata-se de normatividade percebida por alguns como ética, sobretudo pela associação entre conhecimento e equidade, conhecimento e igualdade, aquisição do conhecimento e justiça social, como problematiza Lopes (2015b). Sua sedimentação em tempos atuais conjuga - na esfera do direito e da lei - uma razão pautada na submissão de distintos aspectos da existência aos termos econômicos (MACEDO, 2017, p. 509).

O questionamento a um currículo nacional vem sendo feito por autores críticos contra a prescrição característica das perspectivas instrumentais hegemônicas desde anos de 1970 . Apple (1993), por exemplo, se mantém combativo ante àquilo que julgamos ser uma intensificação das fantasias de controle colonial (BHABHA, 2013). Nas políticas educacionais inglesas (desencadeadas a partir da Lei de Educação Inglesa, de 1993), australianas (publicada no texto Quality education: the case for an education revolution in our schools ${ }^{2}$ ), norte-americanas (Common Core) e brasileiras (Pátria Educadora, BNCC), dentre outras, com maior força a partir dos anos de 1990, como explica Macedo (2016), essa intensificação é sustentada por promessas de cidadania e emprego edificadas numa equação entre qualidade e controle.

A problemática do direito nas políticas de base comum está para além, ponderamos, da simples enunciação de que a política busca corrigir suposta perturbadora frouxidão ou imprecisão dos Parâmetros Curriculares Nacionais (BRASIL, 1998) ou das Diretrizes Curriculares Nacionais Gerais para a Educação Básica (BRASIL, 2013) na definição do que ensinar a todos, como vem sendo reiterado. Ao mesmo tempo, a defesa de que é necessário “(...) normatizar questões de natureza curricular (...) que permanecem ambíguas, exigindo ordenamento claro dos órgãos competentes" (BRASIL, 2014, p. 15) sinaliza para como tal problemática se depara com uma precariedade, que não é resultado de omissão ou de imprecisão provocada pelas mudanças nos grupos que atuaram na produção da BNCC da educação básica ou do próprio Conselho Nacional de Educação na elaboração da Resolução N. ${ }^{\circ}$ 02/2019. O problema aí instado é a impossibilidade mesma de manejar direitos na 
redução da educação ao que deve ser ensinado-aprendido, no bojo deste processo que se arroga a fixar o impossível, ou seja, os conteúdos da formação de professores aos conhecimentos a serem ensinados e aprendidos na Educação Básica e às identidades a serem formadas. A redução da educação a ensino, na iteração de que falta conhecimento (e conteúdo) na formação de todos, torna possível o entendimento de que o sujeito livre, crítico, apto ao trabalho e à atuação social, rebente do acesso àqueles conhecimentos afirmados como essenciais, seja na escola ou nos cursos de licenciatura.

A tentativa de exclusão radical de visões divergentes (consequente, imaginamos, a conhecimentos) daquelas relativas aos que são chamados a pôr selo n“"...] o conjunto orgânico e progressivo de aprendizagens essenciais que todos os alunos devem desenvolver ao longo das etapas e modalidades da Educação Básica" (BRASIL, 2017a, p. 07), é a condição mesma de manejar a ideia de base, conhecimento essencial ou competências a serem desenvolvidas. É condição de se sustentar que “[...] a BNCC soma-se aos propósitos que direcionam a educação brasileira para a formação humana integral e para a construção de uma sociedade justa, democrática e inclusiva." (Idem). Igualmente, são tais afirmações que permitem o entendimento da formação de professores como um processo em que

[...] os professores devem desenvolver um conjunto de competências profissionais que os qualifiquem para colocar em prática as dez competências gerais, bem como as aprendizagens essenciais previstas na BNCC, cuja perspectiva é a de oferecer uma educação integral para todos os estudantes, visando não apenas superar a vigente desigualdade educacional, mas também assegurar uma educação de qualidade para todas as identidades sobre as quais se alicerça a população brasileira. (BRASIL, 2019b)

A ideia de currículo comum faz a crença no direito viver de reduções, como a do binômio básico/comum, reiterado e/ou substituído por outros pares, como comum/diverso, parte comum e parte diversificada, diretrizes/currículos, aprendizagens essenciais/competências. É neste sentido que se jacta "o compromisso da BNCC com a garantia de que os direitos de aprendizagem sejam assegurados a todos os alunos." (BRASIL, 2017a, p. 16). Na afirmação do direito $a$, hierarquias são processadas estruturando como o mundo deve ser, como deve ser o conhecimento a ser acessado pelos sujeitos, que por essa forma de acesso serão constituídos em plenitude. Longe de defendermos qualquer má vontade ou desprezo em torno do que se possa definir como conhecimento, nos distintos contextos em que esse nome é significado, nos incomoda a (insistente e pretensa naturalização de) simplificação do conhecimento numa economia, como assinala Macedo (2017), que submete conhecimento, sujeito e direito a uma creditação. O Parecer CNE/CP No 22/2019, que atualizou a Resolução CNE/CP N $\mathrm{N}^{\mathrm{o}} 2$, de $1^{\circ}$ de julho de 2015, e aprovou a Resolução CNE/CP No 2/2019, indica que, na formação,

[...] é essencial ressaltar que as competências que os professores precisam desenvolver são específicas, e vão além das competências da BNCC. Espera-se, de um bom profissional da área, que ele esteja preparado para articular estratégias 
e conhecimentos que permitam também desenvolver essas competências socioemocionais em seus estudantes, considerando as especificidades de cada um e estimulando-os em direção ao máximo desenvolvimento possível. (BRASIL, 2019b).

A plenitude da formação das crianças e jovens da educação básica é demandada, então, por uma concepção teleológica de conhecimento na simplificação do que seja conhecer a ideia de conhecimento socioemocional. Essa simplificação, em primeiro lugar, oblitera a inscrição histórico-cultural de qualquer conhecimento, a condição valorativa e contextual de todo conhecimento. Pensar o conhecimento como algum elemento disparador de um desenvolvimento "da questão curricular no Brasil (BRASIL, 2017a, p. 09)", ou de uma tal identidade processada no desenvolvimento dos componentes curriculares, é circunscrever o direito à teleologia de um dever ser, que dispensa a ideia de escolha dos sujeitos da escolarização. Nos termos de Lopes (2015a), o direito aí preconizado é dever ser, uma vez que a ideia de direito de aprender e a ideia de direito de decidir sobre o que aprender encontram-se dissociadas, pois nessa via o aprendizado perfaz um direito apenas porque remetido a metas pré-estabelecidas, estranhas às trajetórias escolares e de vida dos estudantes. De tal modo,

Os direitos de aprendizagem e desenvolvimento, que, na segunda versão do documento, estão referidos a princípios éticos, políticos e estéticos, reafirmam a equidade da educação nacional a qual cabe a BNCC assegurar, assim como buscam contemplar as diferentes dimensões da experiência humana que atravessam o currículo. (BRASIL, 2017b, p. 13).

Assim, essa equação simplificadora da ideia de direito pressupõe a existência de algo como "todos" e de todos como um espectro de iguais, necessitados de algo que se produz a despeito do jogo político e sem que se amplie sentidos democráticos (LOPES, 2015a). Em aproximação a essa análise, Macedo (2017, p. 519) considera que a ideia mesma de "[...] haver regras técnicas ou epistemológicas para responder ao que deve ser ensinado opera a eliminação do político com seus antagonismos”. Trata-se da inscrição “[...] do direito reduzido a conhecimentos essenciais e objetivos de aprendizagem e desenvolvimento (...) na perspectiva dos enfoques instrumentais, como dever ser, normatividade, que anula a diferença." (Idem), uma normatividade neoliberal que "[...] é a economização da vida com a expulsão do político.” (p. 518).

Trata-se, em nossa leitura, de uma visão normativa que se constitui como limitante à relação com o outro - para o qual se afirma defender o acesso a direitos $a$-, pela restrição das formas de conhecer a um dado conhecimento dado, concebido como básico para ser (uma identidade). A leitura de que a normatividade assinalada nas bases comuns se volta à expulsão do político está, justamente, no movimento de redução do debate sobre o que é ou pode ser conhecimento, cotidiano, prática, cidadão, ser sujeito. Sem lançarmos mão de 'boas consciências', questionamos a limitação ao direito a ser nas políticas prescritivas, pela restrição a dado conhecimento, frente ao que temos por investimento democrático e pela 
instabilidade deste nome, também, em relação à justiça. Para isto, focalizamos, a seguir, no pensamento de Laclau e Derrida, elementos que julgamos interessantes ao debate e ressignificação de tais termos nas políticas de currículo.

Com Laclau e Derrida, a seguir pomos em tensão as relações entre a normatividade e a alteridade, a moção pelo controle na relação com o imprevisto e incontrolável. A perspectiva da regulação docente, a nosso ver, como todo um terreno de subjetivação projetado pela normatividade curricular, deve ser questionada centralmente pelo esgarçamento da ideia de dever ser que faz desfilar o pressuposto do direito a aprender algo via justiça. Pretendemos, pois, discorrer sobre um pensamento a partir do qual formar por meio de Competências Específicas e Habilidades do Conhecimento Profissional, de Competências Específicas e Habilidades da Prática Profissional e de Competências Específicas do Engajamento Profissional (BRASIL, 2019a) não levam à concretude da formação pretendida por essas políticas. Elas têm sua legitimidade como inscrições da tradição educativa, como uma cogitação de formação de professores no país, no escopo dos discursos/entendimentos pedagógicos no campo, e, por isso, as reconhecemos e criticamos como instituintes de sentidos restritos de formação no campo, como muito se têm discutido (FRANGELLA; DIAS, 2018; BORGES; JESUS, 2020; BALDAN; CUNHA, 2020). Por ora, no entanto, interessa-nos a potencialidade interpretativa para as políticas em torno da projeção normativa, que pensamos pautar sua própria afirmação do controle sobre possibilidades de ser, através da afirmação do direito a ser como um dever ser ao outro, como passamos a discutir a seguir.

\section{Democracia e plenitude ausente no discurso normativo: a defesa do que (me) falta como norma para o outro}

A BNC-Formação e a BNCC da Educação Básica são apresentadas como políticas que "[...] direcionam a educação brasileira para a formação humana integral e para a construção de uma sociedade justa, democrática e inclusiva." (BRASIL, 2017a, p. 7). Elas fazem circular o termo direito numa costura entre a afirmação do direito substantivo constitucional, os direitos humanos, e o direito a aprender e a se desenvolver, para reiterarem a base comum como a expressão, na escola e na formação de professores, da plenitude ausente (porque falta, porque não se assegura) na educação. O pressuposto da plenitude da formação (de uma educação plena em todos os níveis) não é apenas reivindicado; ele excede a tal reivindicação ao constituir o terreno no qual o ser e o dever ser na educação são operáveis numa relação entre normatividade e direito, que reconhecemos como fundante da escolarização Moderna.

Para Laclau (2004), na relação entre normatividade e direito, estão em foco o dever ser, como afirmação cara à expectativa do normativo, e o sendo/ser, como de uma ordem descritiva, não apreensível pela normatividade. O autor adverte para o risco de redução de uma potencialidade interpretativa na abordagem às relações entre proposição de regras e os desdobramentos produzidos em sua tradução, ao mover um enfoque binário, que dissociaria o dinamismo de ambas as forças. A partir de Laclau (2004), a atenção àquilo lido como 
desviante ou estranho a um padrão pode salientar determinada memória normativa, por meio da qual, em suas múltiplas sedimentações, são constituídos prumos ao julgamento do outro. Mas, dentre os motivos pelos quais o autor incita a este cenário está a ideia de que o normativo é posto e sobreposto continuamente, portanto, ele não é soberano a si, de maneira que segue sendo suplementado nas revisitações incessantes que sofre. Igualmente, o mesmo movimento de crítica e suplementação do que se julga por normativo leva a afirmações com potência normativa. Assim, não há produtividade na oposição entre o normativo e o descritivo e, de tal maneira, interessa conceber tais dimensões como em um mesmo movimento.

Como identidades, normativo e descritivo devem ser tomadas como diferença(s) que se constituem uma em oposição a outra. Distância e proximidade tornam-se sinônimos, uma vez que a afirmação do que pode ser um polo ou outro implica a negação de um pelo outro. $\mathrm{O}$ normativo, nesse caso, é pensado como aquilo que indicia o comportamental nos termos de suas faltas (LACLAU, 2004). Ou seja, a pulsão normativa constitui acusação ao que falta ao comportamento de uma atualidade a si, de um apresentar-se em plenitude. A perspectiva normativa visaria ao preenchimento daquilo que um suposto faltoso 'atual', presente a si, operaria, como na falta de um conhecimento básico ao sujeito (professor ou estudante), defendido na ideia de base comum. Nesse sentido, o dever ser diz respeito à busca pela satisfação do que falta ao 'sendo', ao que é lido como um presente comportamental débil. Além disso, a definição de um dever ser ganha vulto como o que se opõe a identidade constituída na defesa da norma, de si ao outro, do que lhe falta ao outro. É nessa distância entre uma preocupação normativa, projetiva e prescritiva ao outro, e o que escapa (lido como falha/falta), que Laclau (2004) pensa a experiência ética. Portanto, entre ser e dever ser em qualquer campo da vida, nunca estamos diante de qualquer conteúdo faltoso a ser prescrito em definitivo para a garantia da harmonia social. A distância que aí se apresenta, infinitamente, é, para Laclau, definida como pertencendo a distância irreconciliável entre o pleno preenchimento do comportamento e o que é afirmado como deficiência. De todo modo, Laclau nos lembra que a busca por aniquilar esta falta implica uma forma de negar o estranho que não é cabível ou pensável para o que diz 'eu' na política, sendo este a subjetivação que denuncia aquele outro interpretado como defeituoso/faltoso/debilitado/a ser corrigido.

O normativo, como diferença (que busca) a ser universalizada, assume a expectativa de preenchimento do faltoso, mas simultaneamente é recoberto na sintomatização da ausência da própria plenitude que visa sanar. A representação da experiência ética do preenchimento é incomensurável, como assinala Laclau (2004), ainda que busque se expressar através de nomes como justiça, verdade ou dever/compromisso com e/ou para o outro. Laclau (2004) pondera que a dimensão ética é marcada pelo incondicionado em um universo condicionado, portanto ela precisa estar desprovida e vazia de todos os conteúdos normativos para ser. A este respeito, o autor pinça uma metáfora de experiência divinal como se desdobrando no vazio de sua plenitude. Se Deus não pode ser localizado, mas está a todo tempo presente, se faz presente em sua ausência, a relação de esvaziamento e preenchimento plenos dizem respeito a uma condição sinônima. Com isto, o autor acena para a precisão normativa como limitada pela sua própria impossibilidade de tudo preencher, na relação com aquilo faltoso 
que julga dominar o significado. O normativo, como busca pela contenção de algo, que estaria sob ou em estado de perda, é absorvido nisso mais amplo e incomensurável ao que se volta para controlar. Trata-se, segundo o autor (Idem), de uma plenitude que se mostra em sua plena ausência.

Nesse sentido, o autor exemplifica como a ocupação de uma fábrica em defesa do direito de trabalhadores locais pode encontrar seu fim na consecução da ocupação e dos direitos almejados. No entanto, se o objetivo maior é militar contra uma opressão mais ampla, refletida localmente, mas que precisa ser combatida globalmente, a greve com resultados exitosos não encontraria seu fim em si mesma. Esta se faria via introdução da perspectiva de equivalência (LACLAU, 2011), na articulação com outros movimentos considerados alinhados em termos de leitura de mundo que, em não possuindo positividade, são constituídos em oposição comum ao que se assume como opressão. No último caso, a militância é permanente ou mais forte, pois apontada para um horizonte furtivo a qualquer manifestação particular que possa trazer satisfação e plenitude. Sobraria, como meio de articulação de uma experiência ética, o envolvimento místico das diferenças envolvidas, aquilo que marca a estrutura de toda experiência. Tal marcação interdita a expectativa de transparência na comunicação com o outro, bloqueia a plenitude consciente e transparente na relação com a alteridade, obsta a certeza teleológica nas decisões. Assim entendemos que, ante a pulsão da différance (DERRIDA, 1991), na construção de equivalências em torno de um nome, é que se marca, no âmbito de uma experiência ético-política, o caráter místico do envolvimento diferencial e da construção de equivalências.

Para Laclau (2004), a relação entre o ético e o normativo implica a concepção do primeiro como movimento de formalização no segundo. O ético se exclui ao normativo, mas é o que lhe dá compromisso, é o que tende a lhe mobilizar como pretensão de plenitude. Como mito social, a projeção ética acusa um desequilíbrio, confirmando-se como equilíbrio via o normativo. Mas, como mito, galvaniza (LACLAU, 2004) diferenças sociais em torno de um objetivo considerado plausível eticamente, um nome. A negatividade do ético é sustentada na atribuição positiva daquilo que é pontuado como problema a ser combatido. No entanto, não há simetria entre a percepção da injustiça e a satisfação de uma justiça plena, embora diferentes nomes sejam disseminados como representações de realização de uma justiça que não se encontra (LACLAU, 2004). A justiça, alçada como meta comum, atuaria como um nome catalisador de distintas afirmações sociais (diferentes agendas que se articulariam em torno de tal nome). O nome justiça, nesse caso exemplar, passaria a enfraquecer a expressão das diferenças envolvidas (dignidade, acesso, educação, direito à aprendizagem etc.), uma vez que não possui identidade última e, portanto, não é capaz de atuar pela interseção de sentidos que o atravessam e erodem.

Se o ético é o incondicional, o condicional do mundo normativo não pode compreenderlhe. $\mathrm{O}$ universo condicionado do normativo opera a leitura de um fundamento para o que deve ser. Por isso, Laclau pondera a impossibilidade de pretender controlar ou gerir a ética, em uma expectativa de normatização. Ou seja, a experiência ética, frente ao seu vazio constitutivo (a tudo), não cabe ao normativo, cuja fundamentação seria a definição precisa 
de um dever ser que se ajusta na eliminação do desvio a si e, portanto, ao que dinamiza uma experiência ética: o atravessamento incessante de distintas experiências particulares.

O normativo adquire função diferencial e o ético uma função equivalencial. Somente assim, quando ambas as dimensões não são vistas como distintas, mas um complexo inerente a esta relação de dimensões particulares-universal, é que se pode pensar a tensão envolvida na afirmação política ético-normativa. Aí reside a possibilidade dinâmica de uma democracia, quando o preenchimento/esvaziamento na significação de um termo ético, como justiça, por exemplo, é porvir (LACLAU, 2004; 2011). Do contrário, com o fechamento eventual de determinada significação, abre-se a possibilidade do totalitarismo, para a univocidade de leituras sobre o que significa determinado nome. Há nisto uma perspectiva de alteridade latente, no primeiro caso marcada pela busca por um diálogo que é conflituoso e não transparente a si; no segundo, um bloqueio, de vez por todas, disso que se lê como externo à articulação política. Portanto, Laclau (2004) destaca que a redução da política a determinado conteúdo de ordem normativa é uma posição inimiga à democracia. Além disso, nessa possibilidade de democracia, inscrita no preenchimento/esvaziamento da significação de um termo ético, a justiça aí edificada como abertura ao porvir não é o direito, pois o direito é calculável e a justiça é incalculável, "ela exige que se calcule o incalculável” (DERRIDA, 2010, p. 30). A experiência do ético - como justiça - é aporética, ela conta com um nãocaminho, é a experiência do improvável (necessária à justiça) na qual "[...] a decisão entre o justo e o injusto nunca é garantida por uma regra." (Idem). De tal modo relacionada à abertura ao porvir como possibilidade de justiça, como um não-caminho, para Laclau $(2004 ; 2011)$, a perspectiva de que uma dimensão ético-normativa não garante nenhum fundamento último é o que oportuniza o conflito constante de distintas visões e, por conseguinte, a reedição contínua do normativo, a sustentação de uma democracia porvir. A possibilidade de significação segue aberta ao social, oportunizando que a afirmação de um fundamento seja uma constante à sociedade, à definição do que ela é.

Isto não implica a opção por um puro decisionismo, o que levaria a um déficit normativo, mas à assunção de que uma vez que não há sujeito, conhecido ou desimpedido na decisão, toda forma de identificação já decide envolta em um conjunto de normatividades constitutivas (LACLAU, 2004). Toda decisão é tomada, em outras palavras, no âmbito de uma ordem normativa, adulterando-a. O sujeito é pensado, nos termos do autor, como a própria distância entre a indecidibilidade estrutural e a decisão. Isto possibilita a concepção de que, sem poder desfazer de um todo normativo ao qual responde (práticas sociais sedimentadas), o sujeito decide sem, com isso, estar totalmente consciente dos desdobramentos causados na e pela decisão. É por isso que operar uma busca pela razão de um tal sujeito, capaz de racionalizar e decidir de tal maneira, é recorrer a uma ficção (LACLAU, 2004).

Para Laclau (2004), vivemos em um mundo cuja sedimentação de práticas impossibilita um tudo conhecer (e conhecer o todo) para refletir sobre o norte à decisão política. $\mathrm{O}$ que se tem é a circunscrição, pela justaposição de distintas práticas, a partir da qual se julga decidir, levando sempre ao deslocamento da estrutura, que não encontra seus limites. Frente às decisões e a partir de tais práticas sociais existentes, a motivação por uma normatividade ou 
opção/escolha tal é de ordem contextual. É, não obstante, marcada por aquilo que se considera como valor a determinado momento na política, algo pensado como melhor do que outra coisa frente a todo um conjunto de determinações consideradas. Para o autor, desde uma posição sistemática e macrossistêmica, não há possibilidade de responder ou justificar a motivação pelas decisões, tampouco a busca por sua compreensão no âmbito de uma razão transcendental interna ao sistema. Se a relação ético-normativa é mobilizada por decisões contextuais, interessa a conceptualização de uma alteridade com a qual se joga (LACLAU, 2000; 2004), não no sentido de supor poder compreendê-la como propriedade, senão como inapreensível e irrecusável na política. A esse respeito, e voltando-se ao tema da justiça, Derrida (2010) introduz a leitura de um movimento de inclusão na relação opaca com o outro, que subsiste a busca pela comunicação através da condição normativa, do que condiciona $o$ normativo e ao normativo.

\section{A justiça como violência traduzida: normatividade e desconstrução}

Para Derrida (2010), somente através desta forma de inclusão/exclusão que se consegue operar na relação com aquilo que se quer fazer ou se julga comum na relação com o ou $a o$ outro. Este normativo habilitador do que se pode tomar por uma relação com a alteridade, para Derrida (2006; 2010), só é possível via tradução. Para o pensador, trata-se de uma nebulosidade interpretativa que não pode ser dissipada por movimentos por clareza, pois no próprio ímpeto esclarecedor reside a contribuição para manter aquilo que constitui a tal nebulosa: a escrita, segundo Derrida (1991). O movimento caro à opacidade deste meio, no qual só se pode investir, pode ser pensado como tradução: dinâmica traidora daquilo mesmo que julga proteger, do sentido que se quer assegurar ou precisar na relação com o outro (DERRIDA, 2010).

No entanto, a notação de que é impossível o acesso transparente ao significado do outro não prescreve hesitação ao pretenso falante/agente/sujeito. Assinala, ao contrário, a impossibilidade de concreção e controle racional sobre uma ontologia pré-estabelecida (por qualquer critério que seja). A impossibilidade de ser antes da relação com o outro está nas proximidades da inviabilidade mesma de ser sujeito consciente de si (portanto, da estrutura, do outro, dos significados, das sedimentações ditas sociais que se lhe supõe anteceder). Considerando, então, a ausência a si de um tal sujeito, resta a contemporaneidade contextual na política, como também adverte Laclau (2004; 2011), uma afirmação ou decisão na política num campo em que disposições sedimentadas constituem o terreno do pensável. Assim, ainda que a subjetivação (porvir subjetivo) assinale uma liberdade, ao mesmo tempo em que descontrola e é urgente, ela não pode ser concebida a esmo, como em uma liberdade absoluta positiva. Noutra via, pode ser tomada como operação a partir de uma incomensurabilidade de normatizações ou condicionamentos discursivos, sedimentados e também opacos nas práticas sociais. Sedimentações que, contextualmente, viabilizam o arrazoamento da decisão, ou seja, possibilitam que a escolha seja feita em dada ocasião, embora seus desdobramentos sejam, em totalidade, desconhecidos (DERRIDA, 2007; LACLAU, 2011). 
Para Derrida (2006; 2010), na busca pela interação, é necessária a (pretensão de) imersão no que se supõe ser a língua, o léxico, a norma que envolve o outro, que faz laço social. Nesta busca, a aspiração ao fazer-se entender pelo outro, endereçar-se a ele, conduz a uma apropriação sempre parcial de sua língua. Nessa relação há um movimento pretensamente consciente ao qual se supõe recorrer, que insta em uma primeira tradução do que se julga referir como meio de ser compreendido, conectado à alteridade; nisso há um desdobramento constante de traduções de traduções, que possibilitam o envolvimento, ao mesmo tempo em que imperfeiçoa a pretensão de transparência na comunicação. Mas esta imperfeição é conduzida precariamente por normatividade(s) que asseguram o mínimo de sensação de comunidade, de ser compreendido e de deliberar, é pelo que se torna (im)possível, provisoriamente, ser.

$\mathrm{Na}$ tensão com o outro, há termos sem equivalência própria para um $e u$ desprovido de tal língua-outra (DERRIDA, 2006; 2010). Na busca à alteridade, são constituídas próteses, versões, equivalências interpretativas do que julga ser do outro para a relação. Nisto há, sempre, segundo Derrida (2010), violência e injustiça, antagonismo e exclusão (LACLAU, 2011), mas também a possibilidade singular de fazer justiça e tentar ser justo, através (e desde sempre) do que se julga por normativo viável/comum/acessível/violento ao outro. Enforceability é um termo acionado por Derrida (2010, p. 8) como dinâmica inerente à pretensão de justiça ao outro através do normativo, como quando visamos ao desconhecido através de uma lei, como uma força de aplicação de execução, que ao ser exercida suspende a própria possibilidade de justiça ao outro. Ela é a "[...] força essencialmente implicada no próprio conceito da justiça enquanto direito, da justiça na medida em que ela se torna lei, da lei enquanto direito" (DERRIDA, 2010, p.8, grifo no original). O direito estaria marcado pela aplicação através da força, quando a justiça deve ser reservada à condição estranha ao próprio direito (em sua pretensão de fazer justiça através da força).

Mas como é possível definir uma lei, com sua força inerente, como justa ou injusta, violenta ou não-violenta? Nos termos da conversa aqui tramada, entre Laclau e Derrida, adentra a perspectiva alemã introduzida pela palavra Gewalt. Derrida (2010) nos faz lembrar que a palavra é tomada pelas facetas de violência e, ao mesmo tempo, de poder do Estado, e que ambas confluem para a ideia de autoridade. A aspiração à justiça, a ser garantida pela normatividade da lei, que se exerce via força, respondendo à pergunta anterior, coloca em questão a origem da necessidade de força de lei, de violência, que é suposta como constituída em resposta a uma pretensa violência e injustiça originárias, que precisam ser combatidas por esta forma de violência sustentada pela busca da justiça. Derrida invoca a leitura de Heidegger sobre a ideia de Díke, postulada por Heráclito, para acenar para um termo pretenso à fundação da ideia de justiça, sendo apreendido pelo pensamento do filósofo grego como justiça, direito, julgamento, pena, castigo ou vingança. Mas, destaca Derrida (2010) que o investimento na significação de Díke implica sua perda na fusão à Eris, esta tomada por conflito, discórdia ou luta, o que é implícito à adikia, o espírito da injustiça.

A afirmação e vigilância sobre o que vem a ser protetivo (contra a violência, a tirania, o desrespeito) é violento e forçoso em relação aquilo que quer defender. A defesa da norma, para a justiça, é também arbitrária, agressiva, injusta e sem regra. Derrida defende a força 
como interessante a ser pensada como força diferido-diferante, como diferença de força, “[...] da força como différance ou força de différance" (DERRIDA, 2010, p.11). Para o autor, não se pode ver a força como atinente ao poder de dada identidade, como possuidora (ou detentora) de origem. Interessa que seja lida como ilocucionária e perlocucionária, performativa, persuasiva e retórica, mas “[...] também e, sobretudo, de todas as situações paradoxais em que a maior força e a maior fraqueza permutam-se estranhamente. E é toda a história" (p.11). Por estes argumentos, Derrida (2010) afirma que a desconstrução é a justiça, pois na medida em que o direito é construível em uma perspectiva que ultrapassa a oposição da convenção à natureza, não pode ser assumidamente fechado em si mesmo. Desta forma, se o direito como normatividade em constante construção e revisitação é desconstruível, de modo que está exposto a distintas leituras e conjecturas e deslocamento, está sujeito a uma alteridade que, em seu ato fundante, quer negar ou limitar. O direito busca, alterando-se como normatividade para a justiça, desencontrando-se, perdendo-se, ao tempo em que é desconstruído como tal.

Uma perspectiva desconstrucionista, no cenário de relações entre justiça e direito, acontece no vão entre a impossibilidade de acesso à justiça e a revisitação constante do direito como promessa de justiça ao outro. A desconstrução seria possível, nesse sentido, como experiência do impossível. A justiça é possibilidade da desconstrução, a estrutura da lei/direito é a oportunidade de exercício da desconstrução (DERRIDA, 2010, p28). Por estes motivos, no movimento em que a desconstrução não se encontra, a justiça também não pode ser, pois como experiência aporética, ambas são inacessíveis à experiência comum. Derrida (2010) diz que a aporia é um não-caminho, reiteramos, mas uma travessia impossível. Esta leitura nos leva à concepção de que a justiça, como a desconstrução, é uma "experiência daquilo que não podemos experimentar" (p.30), ao mesmo tempo em que afirma não ser possível a justiça sem que seja por esta experiência, por impossível que seja, de apelo à justiça. Isto remarca a distância entre uma natureza da justiça e a lei como normatividade, o direito como regra comum. Remarca, como em Laclau (2004), a relação entre um sendo subjetivo (contextual, diferencial, dinâmico) e um dever ser (como movimento de denegação do que é furtivo, como construção de regras e normas).

Segundo Derrida (2010), em dada ocasião de aplicação da legislação a um caso típico, comum, pode ser assegurada a boa execução e força da lei, seu respeito e cumprimento, mas não se pode assegurar que a justiça está sendo feita. Como elemento do cálculo, o direito, a norma a lei, devem existir, ainda que a justiça seja incalculável. A justiça é uma experiência furtiva à certeza de uma regra, é um momento em que a "decisão entre o justo e o injusto nunca é garantida por uma regra" (p30). Derrida (2010) ressalva que a justiça é sempre endereçada ao outro e isto sempre se dá em uma relação de e com a singularidade. $\mathrm{O}$ endereço, pontua, é sempre singular, no entanto, a justiça como direito, como pensada nos termos de uma regra, sempre supõe a generalidade ou universalidade de uma norma, um imperativo a todos. Assim, leva ao questionamento: como pensar a justiça na relação com singularidades insubstituíveis, ao outro e ao eu como outro, no âmbito da definição de normatividades? Como resposta, o autor assinala que uma lei jamais poderá ser considerada legal e justa, pois a perspectiva de legalidade implica a impossibilidade de justiça, como 
discutimos aqui. A certeza de justiça é, segundo Derrida, igualmente impossível, a não ser que suponha a figura da boa consciência (p.32).

Para haver justiça, a decisão judicial/do juiz/de quem decide precisa estar pautada não em seguir a norma, mas em assumi-la e confirmar sua potência no ato interpretativo e traidor daquela mesma que visa fazer cumprir a força (DERRIDA, 2010). A força da justiça ultrapassa, nesse caso, a força de lei, ao extrapolá-la com vistas ao cumprimento de seu fim de justiça. Esta dinâmica se dá por uma decisão que é mobilizada no movimento porvir de justiça, como no porvir democrático a que Laclau (2004) nos invoca ao investimento. Ou seja, a decisão é tomada no terreno indecidível, sem condições de trilhar um caminho previsto de conhecimentos e saberes que poderiam assegurar certa efetividade (DERRIDA, 2010). Interessantes a este artigo, justiça e democracia, embora inapresentáveis, não esperam, mas demandam decisão urgente. Com isto, a decisão para e pela justiça não pode se beneficiar de um tempo impossivelmente suficiente para acontecer.

Tendo em consideração a leitura de Kierkegaard, para quem a decisão é um momento da loucura, Derrida (2010) acena para que a justiça, desdobrada em decisões urgentes alheias ao cálculo, só pode ser aquilo mesmo que não se encontra nas normas, mas é alvo delas, é procurada por elas com vistas a contê-la (no sentido de ter sua propriedade). A justiça, como lógica urgente e constante, não pode ser adquirida por qualquer cálculo, tendo seu fundamento no acontecimento, ou seja, naquilo imprevisto de um vir-a-ser justiça. A justiça é, não obstante, um transbordamento do inapresentável sobre o determinável (DERRIDA, 2010). Ela é da desconstrução, ou como pondera Derrida, é a loucura da desconstrução, pois habita o talvez, a indeterminação na relação com o outro, com aquilo que demandará sempre uma maior flexão teórica, pedagógica, normativa, para interagir com o desconhecido. É preciso, nesse cenário, sempre ter no horizonte a incerteza, precisamente porque a justiça só se encontra na decisão contextual em terreno indecidível, inapresentável e urgente.

\section{Considerações finais}

No contexto em que a aprovação de uma BNC da Formação de Professores vem coroar o excessivo caráter normativo das políticas curriculares para a Educação Básica e para a formação no país, procuramos trazer à discussão questionamentos aos desdobramentos de tal normatividade, por meio da reiteração do direito $a$, inscrita na Resolução CNE/CP N. ${ }^{\circ}$ 02/2019 como direito à educação de qualidade, que se espraia pelas ideias de respeito pelo direito de aprender dos licenciandos, de reconhecimento do direito de aprender dos ingressantes, de direitos humanos, de direitos de aprendizagem e desenvolvimento da BNCC e, por fim, do direito assegurado de concluir a formação sob uma mesma orientação curricular.

A mobilização desses argumentos ensaiaram, neste artigo, uma complicação à ideia de normatividade curricular, que buscamos enfrentar pelo entendimento de que a normatividade curricular na política de formação de professores (BNC-Formação), alinhada à BNCC da Educação Básica, constitui incremento de dispositivos de regulação da docência que tendem 
a limitar a compreensão do que seja educar, atacando a autonomia de professores, escolas e cursos de licenciatura. Assim, pensamos não ser potente a conexão entre o que quer que se nomeie por base na relação com a justiça e com a democracia e defendemos a inexistência de uma unidade comum para as políticas de currículo. Não acreditamos na possibilidade de qualquer texto político se apresentar transparente ou livre de ambiguidades e interpretações, ou como totalidade provocadora de qualquer identidade ou dever ser.

Por essa via, procuramos discutir, com Laclau, que não há algo como sujeitos dados ou onipotentes na política, aptos a decidir em qualquer lugar à parte de dadas formações discursivas. Isto serve a toda forma de identificação (consultores, técnicos, docentes, estudantes etc.) envolvida na defesa de bases comuns frente à promessa de justiça ao outro através da redução ao direito a acessar determinado conteúdo/conhecimento. A normatividade de uma base que marca a pretensão de leitura unívoca, a um trabalho ordenado por uma razão, não é outra coisa senão mais uma violência a restringir outras possibilidades de ser ao outro e ao eu. Daí a considerarmos criticável a proposta de base comum, embora concordemos ser impossível o controle interpretativo do que quer que seja na relação com o outro.

Investimos, com este artigo, na afirmação da impossibilidade de defesa a visões democráticas e justas ao outro por meio da delimitação de propriedades a serem adquiridas sob a pretensão e promessa do direito $a$. Se, como tratamos em diálogo com Laclau e Derrida, estes termos são potencializados quando pensados em sua virtualidade, na condição de promessas possíveis, é porque não concebemos ser viável um encontro pleno com a entidade da democracia e/ou da justiça, de um todo conhecimento capaz de saturar aquilo desconhecido que se visa controlar na política curricular.

Argumentamos que, como promessas em desconstrução, a justiça e a democracia não são conciliáveis com uma transparência cognitiva sobre a alteridade. Mas, a concepção de que o outro é incontrolável, como diferença-diferindo (que bem pode ser lida em dado contexto como movimento social, como expressão de um ou uma estudante/docente, como questionamento irreparável), reitera a dinâmica democrática aberta na própria relação conflituosa, marcada nas experiências cotidianas, nos contextos curriculares, lidos como escolares e/ou para além deles.

Na compreensão destes termos éticos, concluímos reiterando nossa aposta na leitura de que a possibilidade de ser justiça e democracia ao outro está na dinâmica de abertura ao diálogo, ao questionamento, ao refazer constante de perspectivas, à assunção de que o conhecimento é significado, constituído, retroativamente aos questionamentos com os quais lidamos contingencialmente. Nisto não há favor algum àquele desconhecido que buscamos quando propomos algo. O totalitarismo, marcado pela busca da precisão e fechamento à significação da alteridade, é delineado pelo conservadorismo identitário, excluído de si quando fechado ao outro. A amizade ao que por aqui pensamos como democracia consiste na militância pela defesa à política como nunca limitada a qualquer conteúdo. Não havendo um não-fazer, não há vazio normativo na política curricular. Pontuamos a perspectiva de que as dinâmicas normativas seguem em atividade, pois são respostas à impossibilidade de normatização do outro. $\mathrm{O}$ que interpomos, nesse cenário, entretanto, é a crítica à expectativa 
de aumento do controle normativo em oposição às decisões (que são/a serem) tomadas contextualmente. Nos referimos àqueles momentos políticos em que não estamos/estaremos, em que não sabemos/saberemos, e que são dinamizados nas visões de mundo e, portanto, nas subjetivações (sobre ser professor, estudante, cidadão, sujeito, conhecimento) constituídas em respostas/questionamentos sempre insondáveis para uma vontade lógica de denegação da diferença.

\section{Notas:}

1. De acordo com Helena de Freitas, "Esta mobilização, aliada à manifestação da ANDIFES e COGRAD e ainda do GT da Educação Básica da SBPC e suas 60 entidades cientificas, fortaleceu o movimento pela prorrogação, com o objetivo de ampliar os tempos e espaços para novas proposições.”. Disponível em: https://formacaoprofessor.com/2021/08/05/cne-prorroga-prazo-para-adequacao-a-resolucao-02-2019/. Acessado em: 08/08/2021.

2. Educação de qualidade: em defesa de uma revolução educacional em nossas escolas (nossa tradução), Disponível em: http://trove.nla.gov.au/work/26712028?selectedversion=NBD43685897. Uma abordagem pós-crítica é feita em Clarke (2012).

\section{Referências}

APPLE, M.W. The politics of official knowledge: does a national curriculum make sense? Teachers College Record. v. $\quad 95, \quad$ n. $2, \quad 1993 . \quad$ Disponível $\quad$ em: https://pdfs.semanticscholar.org/e995/0baadf5a024cd9195246888a354531cc27c8.pdf

BALDAN, Merilin; CUNHA, Érika Virgílio Rodrigues da. Povoando subjetividades na "nova" política para a formação de professores no Brasil: uma discussão acerca das competências. Série-Estudos, Campo Grande, MS, v. 25, n. 55, p. 51-71, set./dez. 2020.

BHABHA, H. K. O local da cultura. Belo Horizonte: Ed. UFMG, 2013, 441p.

BORGES, V; JESUS, A. P. Fazendo a racionalidade tremer: notas disruptivas acerca da BNC-Formação. SérieEstudos, v. 25, p. 31-50, 2020.

BRASIL. Constituição da República Federativa do Brasil: D.O. 5 de outubro de 1988.

BRASIL. Secretaria de Educação Fundamental. Parâmetros curriculares nacionais - Introdução. Brasília: MEC/SEF, 1998. 126p.

BRASIL. Ministério da Educação. Secretaria de Educação Básica. Diretrizes Curriculares Nacionais Gerais da Educação Básica. Secretária de Educação Básica. Brasília: MEC, SEB, DICEI, 2013.542p.

BRASIL. Por uma política curricular para a educação básica: contribuições ao debate da base nacional comum a partir do direito à aprendizagem e ao desenvolvimento (Versão preliminar). Brasília: SEB/MEC, 2014.

Disponível emhttp://basenacionalcomum.mec.gov.br/documentos/biblioteca/GT_Direitos\%20a\%20Aprendizagem_03 jul2014.pdf

BRASIL. Ministério da Educação do Brasil. Secretaria de Educação Básica. Base Nacional Comum Curricular. Brasília: $\quad$ SEB/MEC, 2017a. Disponível em: http://basenacionalcomum.mec.gov.br/images/BNCC_publicacao.pdf.

BRASIL. Base Nacional Comum Curricular - relatório final sobre o processo de elaboração das versões 1 e 
2. Secretaria de Educação Básica do Ministério da Educação. Centro de Alfabetização Leitura e Escrita CEALE - da Faculdade de Educação da UFMT, Abril de 2017b.

BRASIL. Conselho Nacional de Educação. Conselho Pleno. Resolução No . 2, de $1^{\text {o }}$ de julho de 2015. Brasília: DF, 2015.

BRASIL. Conselho Nacional de Educação. Conselho Pleno. Resolução No 2, de 22 de dezembro de 2017. Brasília: DF, 2017.

BRASIL. Conselho Nacional de Educação. Conselho Pleno. Resolução No 2, de 20 de dezembro de 2019. Brasília: DF, 2019a.

BRASIL. Conselho Nacional de Educação. Conselho Pleno. Parecer No. 22/2019, de 07 de novembro de 2019. Brasília: DF, 2019b.

CLARKE, M. Talkin' 'bout a revolution: the social, political, and fantasmatic logics of education policy. Journal of Education Policy. Vol.27, $\mathrm{N}^{\mathrm{o}} 2,173-19$, March, 2012. Disponível em: http://www.tandfonline.com/doi/abs/10.1080/02680939.2011.623244

COSTA, Hugo H.; FLOREZ, P.; STRIBEL, G. P. Teoria Curricular e a Geografia: convites à reflexão sobre a BNCC. Revista Brasileira de Educação em Geografia, v. 9, p. 86-108, 2019.

CUNHA, Érika. V. R. da; COSTA, Hugo H. C.; BORGES, Veronica. Desconstrução, alteridade e tradução: percursos investigativos nas políticas de currículo. LOPES, Alice C.; SISCAR, Marcos. Pensando a política com Derrida. São Paulo: Cortez, 2018. p. 179-200.

DERRIDA, J. Margens da filosofia. Campinas: Papirus, 1991.

DERRIDA, J. Torres de Babel. Belo Horizonte: Ed. UFMG, 2006.

DERRIDA, J. Força de lei: o fundamento místico da autoridade. São Paulo: Editora WMF Martins Fontes, 2010.

FRANGELLA, Rita de Cássia P.; DIAS, Rosanne Evangelista. Os sentidos de docência na BNCC: efeitos para o currículo da educação básica e da formação/atuação de professores. Educação UNISINOS, v. 22, p. 7 $15,2018$.

GREGOL, H.; LOPES, A. C. Redes políticas de currículo: a atuação da Fundação Getulio Vargas. Práxis Educativa, v. 16, p. 1-18, 2021.

LACLAU, E. Nuevas reflexiones sobre la revolucion de nuestro tiempo. Buenos Aires: Ediciones Nueva Visión, 2000.

LACLAU, E.. Ethics, normativity, and the heteronomy of the law. In: S. Cheng (red.), Law, justice, and power. Between reason and will. Stanford: Stanford University Press, 2004.

LACLAU, E. Emancipação e diferença. Rio de Janeiro: Eduerj, 2011.

LOPES, A. C. Por um currículo sem fundamentos. Linhas Críticas. Brasília, DF, 21 (45), 445-466, mar. 2015a. Disponível em: http://periodicos.unb.br/index.php/linhascriticas/article/view/16735

LOPES, A. C. Normatividade e intervenção política: em defesa de um investimento radical. In: LOPES, A. C.; MENDONÇA, D. de (Orgs.). A teoria do discurso de Ernesto Laclau: ensaios críticos e entrevistas. São Paulo: Annablume, 2015b.

LOPES, A. C. Política, conhecimento e a defesa de um vazio normativo. In: MENDONÇA, Daniel de; PEIXOTO, Leo; LINHARES, Bianca (Org.). Ernesto Laclau e seu legado transdisciplinar. São Paulo: Intermeios, 2017. pp.109-117.

LOPES, Alice C.; MACEDO, Elizabeth F. Apresentação: Uma alternativa às políticas curriculares centralizadas. Roteiro, Joaçaba, v. 46, jan./dez. 2021, E-ISSN 2177-6059. Disponível em: file:///D:/Downloads/Apresenta\%C3\%A7\%C3\%A3o\%20Roteiro\%20-

\%20Uma\%20alternativa\%20\%C3\%A0s\%20pol\%C3\%ADticas\%20curriculares \%20centralizadas\%20(1).p df Acesso em 05/01/2021. 
MACEDO, E. Base Nacional Curricular Comum: Novas formas de sociabilidade produzindo sentidos para educação. Revista e-Curriculum (PUCSP), v. 12, p. 1530-1555, 2014.

MACEDO, E. Base Nacional Comum para Currículos: direitos de aprendizagem e desenvolvimento para quem?. Educação e sociedade, v. 36, p. 891-908, 2015.

MACEDO, E. Base nacional curricular comum: a falsa oposição entre conhecimento para fazer algo e conhecimento em si. Educação em Revista, v. 32, p. 45-68, 2016. Disponível em: http://www.scielo.br/scielo.php?script=sci_arttext\&pid=S0102-46982016000200045\&lang=pt

MACEDO, E. As demandas conservadoras do Movimento Escola Sem Partido e a Base Nacional Curricular Comum. Educação \& Sociedade, v. 38, p. 507-524, 2017. Disponível em: http://www.scielo.br/pdf/es/v38n139/1678-4626-es-38-139-00507.pdf

PEREIRA, T. V. A pesquisa curricular na virada cultural conservadora: os limites da normatividade curricular. Currículo sem Fronteiras, v. 19, p. 910-922, 2019.

TARLAU, R.; MOELLER, K. O consenso por filantropia: como uma fundação privada estabeleceu a BNCC no Brasil. Currículo sem Fronteiras, v. 20, n. 2, p. 553-603, maio/ago. 2020.

VALLE, J. C. A. As Associações Científicas da Educação e a Base Nacional Comum Curricular (BNCC) no Contexto do Sequestro da Democracia Brasileira. Currículo sem Fronteiras, p. 919-949, 2020.

\section{Correspondência}

Hugo Heleno Camilo Costa: Professor Adjunto do Instituto de Ciências Humanas e Sociais (UFMT/Araguaia) e do Programa de Pós-Graduação em Educação (PPGEDU/UFMT). Coordena o Núcleo de Estudos em Currículo, Cultura e Subjetividades (NECSUS/CNPq). Conta com apoio do CNPq, PAFiPesqPG/UFMT e PROAP/CAPES.

Orcid: https://orcid.org/0000-0001-8833-976X

Érika Virgílio Rodrigues da Cunha: Professora Adjunta do Programa de Pós-Graduação em Educação e do Curso de Pedagogia da Universidade Federal de Rondonópolis. Coordena o grupo de pesquisa $(\mathrm{CNPq})$ Políticas de Currículo e Alteridade.

Orcid: https://orcid.org/0000-0002-6648-5261

Texto publicado em Currículo sem Fronteiras com autorização dos autores. 